\title{
“The Saloons Must Go!”."Anti-saloon League” and the Methods of Combating drunkenness at the turn of the XIX-XX centuries
}

\author{
A. M. Zakharova, O. D. Kulikova ${ }^{1}$
}

${ }^{1}$ P. G. Demidov Yaroslavl State University, 14 Sovetskaya str., Yaroslavl 150003, Russian Federation

DOI: $10.18255 / 1996-5648-2021-3-320-333$

Research article

Full text in Russian

The articles based on a wide range of written and visual sources, and investigate the struggle for sobriety on the examples of the most famous organizations - the "Anti-Saloon League" (ASL) in the United States, XIX -XX centuries. In the United States of America in the XIX century, problem of alcoholism among the male population was relevant. Drunkenness has led to increase social problems. In the XIX century, there were public organizations that advocate for the restriction of consumption or the complete rejection of alcohol.

The most influential of them was the "Anti-Saloon League», which aimed to ban the consumption and production of alcohol in the United States. The article considers the activities of the League from the creation in 1893, to the adoption of the "prohibition law" in the United States in 1919-1920. The authors pay special attention to the League's relations with the church and politicians, showing the role of the ASL in the adoption of prohibition. The article contains information about the leaders and activists of the organization (such as Wayne Wheeler, William Anderson, William Johnson, Ernest Cherrington), and the methods they used in the fight for sobriety. The «Anti-Saloon League» promoted intolerance towards alcohol, alcoholics and alcohol manufacturer. For that purpose, ASL held rallies, published newspapers and magazines, where printed cartoons, songs, tragic stories, and articles about the harmful effects of alcohol.

The League actively worked with young people and insisted for the introduction lessons of alcohol temperance in schools and universities. One of ways to fight for sobriety was discredit alcohol manufacturer through insults, provocations, nationalist attacks, etc. Some members of the League organized pogroms of drinking establishments. For acceptance the law on the prohibition of alcohol ASL practiced bribery and pressure to politicians, achieving the adoption of prohibition laws at the state level, and then at the national level. They tried to establish international relations with sobriety fighters from European countries. The result of many years of struggle was the adoption so-called "prohibition» in the United States. The leaders of the "Anti-Saloon League» made a significant contribution to the development of this law.

Keywords: USA; sobriety; Anti-saloon League; alcoholism; prohibition

\section{INFORMATION ABOUT AUTHORS}

\author{
Zakharova, Alena M. | E-mail: Alyona.Zakharova.mail@mail.ru \\ Freelancer \\ Kulikova, Olga D. E-mail: kulikovao@rambler.ru \\ Cand. Sc. (History), Associate Professor
}

(C) Zakharova A. M., Kulikova O. D., 2021

This is an open access article under the CC BY license (https://creativecommons.org/licenses/by/4.0/) 


\title{
«Салуны должны уйти!». Антисалунная лига и методы борьбы с пьянством на рубеже XIX-XX века
}

\author{
А. М. Захарова, О. Д. Куликова ${ }^{1}$
}

${ }^{1}$ Ярославский государственный университет им. П. Г. Демидова, ул. Советская, 14, Ярославль, 150003, Российская Федерация

DOI: 10.18255/1996-5648-2021-3-320-333

Научная статья

УДК 94(73)

Полный текст на русском языке

В статье на основании широкого круга письменных и изобразительных источников изучается борьба за трезвость в США в конце XIX - начале XX века на примере одной из самых известных организаций - Антисалунной лиги (АСЛ). В Соединенных Штатах Америки в XIX веке рост алкоголизма среди мужского населения привел к ряду социальных проблем. В XIX веке появляются общественные организации, выступающие за ограничение потребления или полный отказ от алкоголя. Самой влиятельной из них стала Антисалунная лига, ее целью был запрет на употребление и производство алкоголя. В статье рассматривается деятельность Лиги от ее создания в 1893 г. до принятия в США «сухого закона» в 1919-1920 гг. Особое внимание авторы уделяют связям Лиги с церковью и политиками, показывая роль АСЛ в принятии «сухого закона». Рассказывается о лидерах и активистах организации (таких как Уэйн Уилер, Уильям Андерсон, Уильям Джонсон, Эрнест Черрингтон) и методах, которые они использовали в борьбе за трезвость. Антисалунная лига вела пропаганду нетерпимости по отношению к алкоголю, алкоголикам и производителям спиртного. Для этой цели АСЛ проводила митинги, издавала газеты и журналы, где печатала карикатуры, песни, трагические рассказы, медицинские статьи о пагубном воздействии алкоголя. Лига активно работала с молодежью и настаивала на введении уроков воздержания от алкоголя в школах и университетах. Одним из способов борьбы за трезвость была дискредитация производителей алкоголя путем оскорблений, провокаций, националистических нападок. Некоторые члены Лиги устраивали погромы питейных заведений. Ради принятия закона о запрете спиртного АСЛ практиковала подкуп и давление на политиков, добиваясь принятия законов о запрете на уровне штатов, а затем и на национальном уровне. Были попытки наладить международные связи с борцами за трезвость из стран Европы. Итогом многолетней борьбы стало принятие в США так называемого «сухого закона».

Ключевые слова: США; трезвость; Антисалунная лига; алкоголизм; сухой закон

\section{ИНФОРМАЦИЯ ОБ АВТОРАХ}

Захарова, Алёна Михайловна

Куликова, Ольга Владимировна
E-mail: Alyona.Zakharova.mail@mail.ru

Независимый исследователь

E-mail: kulikovao@rambler.ru

Кандидат исторических наук, доцент 
Захарова А. М., Куликова О. Д.

C начала XIX века в США наблюдался рост потребления спиртного. В 1820-е гг. американцы стали массово производить дешевый виски из кукурузы. Соответственно выросло количество спиртовых заводов в стране. Тогда же появилось Движение воздержания, были организованы первые общества борьбы за трезвость, которые ратовали за умеренное употребление алкоголя. Ситуация обострилась в последней четверти XIX в. В страну хлынул поток мигрантов из Европы - Германии, Ирландии, Италии, которые привезли в США свои традиции потребления спиртного. Резко возросло количество питейных заведений: трактиров, пабов, салунов; часть из них открывалась именно приезжими. Салун в конце XIX века стал своеобразным символом порока и пьянства.

Иммигранты, как правило, селились в больших городах на востоке страны. Многие исповедовали католицизм или иудаизм. Американцы были в большинстве своем протестантами и жили в небольших городах и сельских районах. Культурные и религиозные различия не всегда принимались населением. В обществе развертывалась внутренняя культурная война, которая повлияла на Движение за трезвость: пьянство ассоциировалось с традициями мигрантов.

Массовое производство алкоголя, развитие рекламы и возможность проводить досуг в питейных заведениях привели к тому, что к концу XIX в. число хронических алкоголиков возросло до трехсот тысяч, а количество выпитого алкоголя на человека в год равнялось 10 литрам стандартного 80-градусного ликера. Современники отмечали, что алкоголизм привел к росту социальных проблем: потере работы, бедности, распаду семей, росту числа преступлений и повышению уровня смертности. Изменились и цели Движения за трезвость - всё больше организаций стали бороться за полный запрет на продажу и производство спиртного.

Среди организаций, лоббирующей запрет на производство и продажу алкоголя, выделялась Антисалунная лига (АСЛ). Она внесла вклад в создание и ратификацию восемнадцатой поправки к Конституции, что означало принятие «сухого закона» ${ }^{2}$. Девизом АСЛ стала фрраза: «Салуны должны уйти!»

Антисалунная лига была создана в 1893 г. как государственное общество в Оберлине, штат Огайо. Ее влияние настолько быстро распространялось, что в 1895 г. она превратилась в Национальную организацию [1, p. 127-128]. Сильнее всего объединение выступало в районах, где преобладало сельское хозяйство. Оно получало большую поддержку от пиетистских ${ }^{2}$ протестантских священников и их общин. Их члены имели

1 «Сухой закон» в США - национальный запрет на продажу, производство и транспортировку алкоголя, который действовал в США в 1920-1933 гг. Запрет был введён Восемнадцатой поправкой к Конституции США 16 января 1919 г.

${ }^{2}$ Пиетизм - изначально движение внутри лютеранской и реформатской церквей, характеризующееся приданием особой значимости личному благочестию, религиозным пере- 
связи с Конгрессом и могли влиять на принятие того или иного закона, что привело к успеху.

АСЛ являлась протестантским церковным движением [2, р. 84]. Эрнест Черрингтон, один из лидеров АСЛ, говорил, что лига была «объединенным церковным воином, занимающимся свержением торговли спиртным» [3, р. 99-103]. АСЛ совместно с церквями вырабатывала методы борьбы. Так, например, она организовала для пасторов в более чем 2000 церквях Иллинойса обсуждение способов пропаганды Движения за трезвость [1, р. 56-58]. Вся деятельность Лиги считалась нравственной, потому что «она работала, чтобы исполнить волю Господа» [4, р. 279-280].

Основатель и первый глава Лиги Говард Хайд Рассел считал, что лучшее руководство выбирается, а не избирается. Он строил организацию снизу вверх, фрормируя местные объединения и поднимая наиболее перспективных людей к руководству на областном и государственном уровнях. Именно он впоследствии наставлял основных лидеров организации Уэйна Уилера и Эрнеста Черрингтона. Кроме АСЛ, он учредил «Легион Линкольна», который пропагандировал подписание детьми и молодыми людьми обетов воздержания [5, р. 90]. АСЛ являлась беспартийной организацией и принимала в свои ряды мужчин и женщин.

Лидеры организации считали одним из способов борьбы с пьянством пропаганду ненависти и нетерпимости по отношению к алкоголю, пьяницам, производителям и распространителям алкогольной продукции [6, p. 26-27]. В 1909 г. была создана "Американская издательская компания» в Вествилле, штат Огайо, где находилась штаб-квартира Лиги. В течение первых трех лет своего существования издательство выпускало около 250000000 страниц в месяц. В 1910-х гг. АСЛ издавала газеты («Американский патриот», «Новая республика», «Национальная ежедневная газета») и журнал «Американская проблема». Они рассказывали про «героев битвы против распространения спиртного» и «врагов лиги», призывали своих читателей присоединиться к борьбе за трезвость, просили посылать письма политикам, печатали статьи о хроническом алкоголизме, его последствиях с медицинской и моральной сторон, публиковали истории людей, пострадавших из-за пьянства в семье.

В пример можно привести обложки газеты «Американский патриот» за 1912 г. На одной из них изображены мальчик и девочка, которые зимой стоят перед витриной магазина с теплыми пальто; их родители, по-видимому, не могут позволить купить им верхнюю одежду. По изображению можно понять, что редакторы АСЛ хотели обратить внимание на салуны и бары, которые забирают долю дохода у семьи: справа видна вывеска питейного заведения в фроре бокала, а надпись внизу раскрывает

живаниям верующих, ощущению живого общения с Богом, а также ощущению постоянного нахождения под строгим и бдительным «Божьим оком». 
Захарова А. М., Куликова О. Д.

нам смысл обложки - «тяжелая тень упала на детей» [7]. На первой странице майского выпуска 1912 г. мы видим диалог хозяина салуна и пивовара, которые стоят на могилах пьяниц. Владелец бара в красной жилетке и белом переднике жалуется на то, что лучшие клиенты уходят из жизни почти каждый день; пивовар предлагает ему пополнять ряды гостей салуна школьниками, которые изображены на заднем плане. Обложка призывала людей обратить внимание на то, что нахождение питейных заведений в городах может в худшую сторону повлиять на привычки и мысли молодого поколения [8].

После того как руководителем вместо Говарда Рассела в 1903 году стал методистский священник Пэрли Бейкер, он занялся сбором средств для создания крупной информационной кампании. Ее основной целью была демонизация производителей алкогольных напитков [4, р. 34-36]. Многие пивовары в США имели немецкое происхождение; Бейкер говорил, что «немцы едят как обжоры и пьют как свиньи» [9, p. 183-184]. На плакатах АСЛ их изображали в виде чертей, чьим единственным интересом стало производство пива в США и распространение алкоголизма [10]. Он утверждал, что «лига пришла не просто для того, чтобы создать небольшие местные объединения или обеспечить принятие нескольких законов, а для того, чтобы окончательно решить проблему со спиртным» $[11$, p. 78-79].

Известно, что многие политические деятели делали щедрые пожертвования в организацию взамен на популяризацию их политики в печатных изданиях Лиги. Лига не скрывала того, что иногда подкупала политических деятелей, если того требовала ситуация. Обычно такие меры предпринимались, чтобы оказывать давление на должностных лиц. На их противников она могла обрушить шквал оскорблений, сплетен и лжи, для укрепления позиций своего лидера. По мнению членов организации, достигнутая в итоге цель, а именно запрет на продажу алкоголя, оправдывала многие сомнительные действия [6, р. 28].

Третьим руководителем Антисалунной лиги стал Уэйн Бидвелл Уилер, назначенный на должность президента АСЛ в 1904 г. по настоянию основателя организации Г. Х. Рассела. Рассел увидел в Уилере «любящую, энергичную самоотверженную душу, которая жаждет помочь другому человеку» [12, р. 38-39]. Находясь на своем посту, Уилер выступал за то, чтобы сторонники запрета строго и безжалостно применяли законы, а не пытались ограничить потребление алкоголя посредством лечения и образования. Он был сторонником строгого и решительного принуждения в вопросе отказа от спиртного и писал, что «желает самых суровых наказаний, самой агрессивной политики, вплоть до призыва армии и фрлота, проведения самого беспощадного расследования» в отношении любого, кто связан с алкоголем [13, р. 144-145]. 
«Салуны должны уйти!»...

С первых лет своей карьеры в Лиге Уилер проявлял прекрасные организаторские способности и политическую хватку. Он стал инициатором политики давления, которой позднее дали название «Уилеризм».

Уилеризм включал в себя такие методы, как угроза опорочить партию в глазах избирателей, одобрение и финансирование противников и раскрытие личной информации. Все это делалось ради того, чтобы получать от лиц, находящихся у власти, поддержку в ограничении торговли алкоголем. Так, Уилер и члены АСЛ провели кампанию против Майрона Т. Херрика, который баллотировался на пост губернатора штата Огайо в 1906 году. Сам кандидат являлся республиканцем и консерватором. Он согласился поддержать местный проект Лиги с условием некоторых изменений, делающих запрет не таким строгим. Херрик прокомментировал это тем, что так законопроект точно пройдет на слушаниях, но членов Антисалунной лиги это не устраивало, и они направили свои силы и финансы на поддержку его оппонента демократа Джона М. Паттисона, который являлся ярым сторонником воздержания. В итоге второй кандидат победил и этот результат стал первой значительной победой АСЛ [14].

Под руководством Уилера лига полностью сосредоточилась на достижении запрета. Объединение поддерживало на выборах кандидатов, полностью основываясь на их позиции относительно запрета. При этом игнорировалась их партийная принадлежность или взгляды по другим вопросам. Уилер считал, что единственный способ противостоять влиянию производителей алкоголя - сосредоточиться на достижении национального запрета любыми необходимыми средствами. Именно в годы его нахождения во главе Антисалунной лиги было налажено множество двусторонних связей с государственными чиновниками, законодателями и членами Конгресса. С их помощью он повлиял на отмену Конгрессом вето на закон Уэбба-Кеньона. Этот акт запрещал транспортировку алкогольных напитков в штаты, которые имеют местные законы о запрете спиртного, даже в небольших количествах, предназначенных для индивидуального потребления. Президент США Уильям Говард Тафрт 28 февраля 1913 г. наложил на него вето, полагая, что это поможет развиваться межгосударственной торговле. Но Сенат и Палата представителей совершенно неожиданно проголосовали против его наложения, тем самым показав, насколько могущественными стали сторонники АСЛ и Движения запрета [15, р. 279].

За этим последовало введение национального подоходного налога, санкционированного 16-й поправкой. До 1913 г. федеральное правительство зависело от налогов на спиртные напитки на $40 \%$ годового дохода, но с подоходным налогом этот аргумент исчез [16, p. 120]. По мере того как сила Движения воздержания продолжала расти, Уилер расширял влияние АСЛ через другие союзы трезвости. Он поддерживал женское 
Захарова А. М., Куликова О. Д.

избирательное движение в надежде на то, что женщины проголосуют за кандидатов от Антисалунной лиги, когда придет время. АСЛ сотрудничала и проводила совместные митинги с другими организациями, например с «Женским христианским союзом трезвости», на которых призывали употреблять воду вместо алкоголя. В итоге, после десятилетий попыток и усилий, Лиге и другим объединениям удалось добиться принятия в 1919 г. Восемнадцатой поправки, которая запрещала производство, транспортировку и продажу алкогольных напитков. Благодаря помощи членов АСЛ в 1920 г. ратифицировали девятнадцатую поправку к Конституции США, предоставляющую женщинам право голоса [12, p. 78].

В начале 1920-х гг. Уилер обладал достаточной властью. Он принимал участие в разработке закона Востеда, который предусматривал средства для обеспечения выполнения поправки о запрете, а также в составлении федеральных и местных законов, которые уточняли механизмы запрета. Влияние его распространилось и на Бюро по запрету алкоголя, предоставляющее ему контроль над кадровыми работниками, нанимающими сотрудников правоохранительных органов, ответственных за выявление и задержание производителей, распространителей и продавцов спиртных напитков. Как активный член Бюро, он был против добавления к промышленному алкоголю неядовитых денатуратов, таких как мыло, или других безвредных веществ. Он утверждал, что правительство не обязано защищать жизнь граждан, если они нарушают закон, употребляя алкоголь. В результате, уже во время введения «сухого закона», погибло от 10000 до 50000 человек от употребления промышленного спирта, после чего Уилер говорил, что жертвы добровольно совершили самоубийства [13, p. 203-205]. Его бессердечное отношение и отказ идти на компромисс в вопросе введения сухого закона начали менять отношение общественности к Антисалунной лиге, и влияние Уилера стало ослабевать. Кроме того, в 1926 г. члены Конгресса поставили под сомнение расходы Лиги на некоторые кампании в поддержку кандидатов. И вскоре Уилеру пришлось покинуть свой пост. Он умер в 1927 г., и после его смерти Лига отказалась от его политики. Тем не менее Уэйн Уилер сыграл важную роль в превращении Лиги в первую мощную группу политического давления в стране.

Ради осуществления цели участники Лиги использовали разные методы, в том числе неправомерные. Так, например, в 1909 г. несколько членов организации прибыли в Феникс, чтобы надавить на местную полицию, требуя отказать в выдаче лицензий заведениям, нарушающим режим или обслуживающим женщин и несовершеннолетних. Они предоставили свидетелей, которые дали показания о нарушениях. Одним из свидетелей был Фрэнк Шиндельбауэр, подросток из бедной семьи, который согласился указать на салуны, продававшие ему спиртное. В итоге заведения потеряли свои лицензии. Однако владельцы баров провели свое рассле- 
дование и выяснили, что мальчик лжесвидетельствовал, после чего его заключили в тюрьму. Случай получил широкий общественный резонанс. Пресса изобразила Шиндельбауэра «невинным орудием» Антисалунной лиги, и он был помилован [17, р. 141].

Одним из самых успешных лоббистов Антисалунной лиги был Уильям Андерсен. Он начал пропагандировать «сухой закон» в штате Мэриленд, и с его помощью в 1893-1900 гг. было закрыто более тысячи питейных заведений в Балтиморе. Благодаря его действиям, лидеры организации пригласили его в Нью-Йорк, чтобы направить усилия на самый крупный город в США и повлиять на всю страну. Тактика Андерсена заключалась в использовании ложных слухов, поддельных документов, психологических атак на противников и запугивания. Один из пострадавших, спикер собрания штата Тадеуш Суит, писал, что Андерсон использовал воинственную тактику агрессивного политика, которой было достаточно, чтобы «кровь застыла в жилах, а волосы встали дыбом» [18, p. 17].

Агрессивные методы Уильяма Андерсона по отношению к законодателям и духовенству, которые не сотрудничали с ним, вызывали отвращение у многих людей. Противники обвиняли его в использовании Антисалунной лиги для личного продвижения, называли «врагом общественного блага", «грязным политиком» и «антихристом АСЛ» [19]. Однажды он сообщил 300 газетам информацию о том, что секретный «Фонд грязи» (Slush Fund) ${ }^{3}$ специально был создан противниками «сухого закона» для того, чтобы подкупать Нью-Йоркских законодателей. Он утверждал, что им дали деньги за голоса против закона, продвигаемого Лигой, и хотел вынести вопрос на обсуждение, появившись в Олбани на слушаниях по антиалкогольному законодательству. Но председатель собрания запретил Андерсону давать показания, если он не представит доказательств своих утверждений. Не имея возможности доказать это, он был вынужден стать обычным наблюдателем слушания, а информация в газетах была признана ложной [1, р. 78].

Еще одна стратегия Уильяма Андерсона состояла в том, чтобы настаивать на "местных альтернативных" законах запрета на алкоголь в небольших городах. Но после вступления США в Первую мировую войну ему пришлось остановить осуществление своей программы и создать новую стратегию, которая заключалась в приравнивании «сухого закона» к патриотизму. В годы войны Лига часто использовала эмоциональную

${ }^{3}$ Фонд грязи (черный фронд) - фронд или счет, который не учитывается должным образом, например деньги, используемые для коррупционных или незаконных целей, особенно в политической сорере. Такие средства могут быть скрыты и содержаться отдельно от денег, которые используются в законных целях. Государственные или корпоративные чиновники могут использовать средства «грязи» для того, чтобы незаметно платить влиятельным людям в обмен на предварительную информацию (например, непубличную информацию в финансовых операциях) и другие услуги. Сами средства не могут храниться в тайне, но источник этих средств, способ их приобретения или цели их использования могут быть скрыты. 
Захарова А. М., Куликова О. Д.

патриотическую риторику, основанную на антигерманских настроениях в обществе. В одном из памфлетов Лиги Андерсон писал, что «торговля спиртным является неамериканской, а прогерманской, преступной, расточительной, развращающей молодежь и разрушающей дома». Другая листовка спрашивала: «Как может любой лояльный гражданин, будь он «мокрый» или «сухой», голосовать за торговлю, которая помогает прогерманскому Союзу?» [20, р. 44]. Еще одна цитата в газете «НьюЙорк Таймс» гласила: «Все в этой стране, что является прогерманским, является антиамериканским. Поэтому все прогерманское должно уйти» $[21$, p. 6].

В своих речах У. Андерсон нападал на евреев, ирландцев, итальянцев и других, чья культура обычно включала употребление алкоголя. Он описывал их как «немытых и диких иностранцев, которые не имеют никакого представления о духе Америки» [22, р. 4]. Крайне негативно Андерсон относился к католикам и обвинял католическую церковь в «нападении на закон и порядок». Он говорил, что католические лидеры пытаются отомстить протестантам путем срыва попыток ратификации «сухого закона» и возвращения салунов [23, р. 44].

Одним из знаменитых лидеров Антисалунной лиги был Уильям Юджин Джонсон. В 1889 г., когда штат Небраска, где в то время он проживал, был вовлечен в дебаты по поводу принятия местного закона о запрете, Джонсон выдал себя за противника «сухого закона», чтобы получить информацию от владельцев пивоварен и салунов. Это стало его визитной карточкой, и в дальнейшем он часто пользовался приемом, выдавая себя за пьяниц или иностранцев, таким образом собирая инорормацию против владельцев заведений [24]. Работая агентом индейской службы США в Оклахоме (1908-1911 гг.), он устраивался в салуны уборщиком, чтобы записывать все беспорядки, происходящие по вине алкоголя и азартных игр. Газеты называли его «джентльменом с поступью пантеры» за использование тактики «кошачьей» скрытности в преследовании подозреваемых на территории Оклахомы и за то, что на его ботинках всегда были резиновые каблуки. Таким образом, он получил прозвище - «кошачья лапка» (Pussyfoot) и под таким именем стал известен среди участников Движения Воздержания. Он добился вынесения более 4400 обвинительных приговоров [25, р. 102] владельцам заведений и конфисковал более 90000 бутылок ликера [26, р. 1]. Пострадавшие объединились, чтобы предложить вознаграждение за его смерть в размере 3000 долларов США. Узнав о награде, Джонсон перешел к другой тактике - ночным взломам, с помощью которых ему удавалось проникнуть в трактиры и бары незамеченным и устраивать в них погромы [25, р. 104].

После его отставки с Федеральной службы за чрезмерно радикальные методы борьбы с алкогольными заведениями он переехал в Канзас, 
где разработал новые методы, которые впоследствии широко использовались Лигой. Например, он писал лидерам, выступающим против «сухого закона», называя себя пивоваром, и просил совета, как победить активистов Движения трезвости. Затем Джонсон публиковал полученные письма, чтобы смутить и дискредитировать оппозицию. Своими не всегда честными методами Джонсон гордился, открыто признавая, что ему приходилось лгать ради поддержки “сухого закона», и не стыдился этого [27].

В начале XX в. цели Антисалунной лиги стали более глобальными принятие «сухого закона» не только в США, но и во всем мире. Ради пропаганды своих идей решено было отправить Уильяма Джонсона в Англию, как творческого человека и прекрасного оратора. 13 ноября 1919 г. он был схвачен толпой студентов-медиков во время выступления в Эссекс-холле и пронесен на носилках по улицам Лондона, прежде чем его успела спасти полиция. Во время драки он потерял глаз, так как один из учащихся бросил в него камнем. Сам Джонсон называл утрату хорошей инвестицией в дело запрета, что дало ему еще большую известность и сделало его мучеником за дело запрета. В апреле 1921 г. Джонсон был освистан на митинге во время кампании за ужесточение законов о запрете. Очевидцы говорили, что толпа была настолько враждебна, что Джонсона пришлось окружить полицией и сопроводить в Детройд [27]. Причина такого недовольства англичан заключалась в нежелании принимать американскую политику и в том, что в Англии в то время не было таких масштабных проблем с пьянством, из-за которых следовало принимать столь радикальную меру, как полный запрет алкоголя.

В 1912-1926 гг. Джонсон работал главным редактором 35 изданий АСЛ, был директором издательской компании Лиги - «Эмиссия», тесно сотрудничал с Уэйном Уилером и Эрнестом Черрингтоном, работал над выпуском большого издания «Стандартной энциклопедии проблем алкоголя».

Однако стоит отметить и более мирные способы борьбы со спиртным, используемые АСЛ. Так, например, членами Лиги было написано несколько песен, которые распевались в церквях, на митингах или в семьях по праздникам. В источниках мы можем увидеть такие песни, как «Мир становится сухим», «Вперед, солдаты Воздержания» и «Добро пожаловать» [28]. Первая песня традиционно пелась на собраниях АСЛ, вторая была гимном всех борцов за трезвость, третью распевали как колыбельную. Кроме мелодий, активисты писали рассказы в прозе на тему губительных последствий употребления алкоголя. Например, «Мать Бесси», «Обвиняется в убийстве», «Холодная ванна Луи». Все эти произведения были написаны для детей, чтобы повлиять на них с самого раннего возраста. В каждой из историй показаны разные жизненные ситуации, происходившие по вине алкоголя, и делалась попытка научного объяснения вредного воздействия алкоголя на здоровье человека 
Захарова А. М., Куликова О. Д.

и общество, но простыми понятными словами. В первом рассказывается о том, что матери приходится объяснять маленькой дочке, почему она должна отдать ее в детский приют: отец тратил все заработанные деньги на спиртное и после его смерти семья осталась без денег. «Алкоголь заставляет человека хотеть больше и больше, пока у него не появляется постоянный голод, который часто бывает сильнее, чем любовь мужчины к его семье», - объясняется в произведении [29]. Во втором рассказе обвиняемый в убийстве жены на суде заявил, что виновны в случившемся салуны и правительство, которое их не закрыло. Ведь если бы не салуны, он никогда не стал бы пьяницей. Он отмечал: «Вы узаконили салуны, которые сделали меня пьяницей и убийцей, и вы виновны со мной перед Богом и людьми за убийство моей жены» [30]. В третьем рассказе пьяный главный герой плыл на лодке с маленькой дочкой, не смог справиться с веслами, раскачав лодку, и девочка выпала за борт. Ее спас друг отца, доктор, который разъяснил виновнику, что алкоголь - яд, мешающий работе мозга: «Когда наши мозги говорят нашим рукам что-то делать, они должны быть в хорошем состоянии, или они прикажут нашим рукам сделать что-то ужасное. Ваш мозг подобен двигателю машины, и, если вы хотите, чтобы ваша машина работала хорошо, вы не должны ломать двигатель» [31].

Кроме песен и рассказов, Антисалунная лига выпускала черно-белые «мультфильмы» (комиксы), которые по фракту являлись карикатурами и зарисовками на тему проблемы алкоголя и его воздействия на население. В одном из них мы видим образ "выпивки», тонущей в публичном осуждении, и его единственными друзьями являются только бездарность, бедность и порок. В другом показана "выпивка", которая выстроила свою алкогольную империю в каждом штате как домино, в виде книг, и только могущественная рука Конгресса может разрушить постройку. На еще одном изображении можно увидеть, как мать и ребенок страдают от бедности, не могут себе купить даже буханку хлеба стоимостью пять долларов. Объясняется это тем, что миллионы бочек отборной пшеницы расходуются на выпивку, тем самым ее не всегда хватает на производство хлебобулочных изделий; в результате они дорожают и становятся не по карману бедным семьям [32].

Следует обратить внимание и на листовки, которые составлялись как статистические данные о потерях во время Балканской войны 1912-1913 гг. ${ }^{4}$ по вине алкоголя. На первом листе описываются выводы врачей, находившихся рядом с солдатами во время военных действий. Врачи утверждали, что у мужчин, которые пили перед боем, раны заживали дольше, чем у тех, кто этого не делал. Кроме того, несчастные случаи

${ }^{4}$ Балканские войны - две войны, произошедшие в 1912-1913 гг. незадолго до Первой мировой войны, в результате которых страны Балканского полуострова потеснили турок с европейской территории. 
чаще всего происходили с хроническими алкоголиками, видимо, потому, что их действия были неточны из-за дрожи в руках и спутанных мыслей. Врачи писали, что спиртные напитки ухудшают кровь, раны заживают дольше, а сердце изнашивается в два раза быстрее и смерть наступает раньше. Также алкоголь иногда вызывал у мужчин приступы бреда, проявление которых серьезно угрожало жизни [33].

Ведущим журналистом и активным участником Антисалунной лиги, выступающим за мирные методы, был Эрнест Черрингтон. Он был убежден в том, что проблема алкоголизма должна быть решена путем просвещения общественности и правильного воспитания школьников и студентов. В 1920-х гг. Черрингтон издал небольшую брошюру в виде двухстраничного сложенного листка под заголовком «Образование сохранит запрет в Конституции», где рассказывал о необходимости включения уроков по воздержанию в школах, колледжах, молодежных церковных обществах, воскресных школах и университетах. Он отмечал, что образование способно разрушить вековые традиции употребления алкоголя [34].

Антисалунная лига была первой группой давления в США, организованной вокруг одного вопроса. Она применяла как мирные, так и агрессивные методы борьбы за «сухой закон», действуя через местные и национальные законодательные органы власти, используя широкую пропаганду в прессе и взаимодействие с другими организациями. Активисты Лиги видели себя проповедниками, выполняющими свой религиозный долг по уничтожению алкоголя в Северной Америке [35, p. 4]. В итоге АСЛ все же сумела достигнуть своей цели и 18-я поправка к Конституции в 1920 г. была принята. На пути к результату Лига игнорировала многие социальные проблемы, которые вызывал «сухой закон», такие как организованная преступность, бутлегерство, сокращение государственных доходов и смертность от некачественного подпольного спиртного. Все это подорвало общественное влияние организации, и она утратила свою власть. В 1948-1950 гг. объединение называлось Лигой трезвости, в 1950-1964 гг. - Национальной лигой трезвости, а с 1964 года - американским Советом по проблемам алкоголя. В настоящее время организация продолжает существовать и выполнять свою первоначальную задачу.

\section{Ссылки}

1. Odegard P. H. Pressure Politics: Story of the Anti-Saloon League. N. Y.: Columbia University Press, 1928. 255 p.

2. Rumbarger J. J. Profits Power and Prohibition: Alcohol Reform and the Industrializing of America, 1800-1930. N. Y.: State University of New York Press, 1989. $298 \mathrm{p}$.

3. Cherrington E. History of the Anti-Saloon League. Westerville: Yearbook, 1913. $134 \mathrm{p}$. 
Захарова А. М., Куликова О. Д.

4. Chalfant H. The Anti-Saloon League - why and what? // The American Academy of Political and Social Science. Pennsylvania. June 12, 1923. No.109. P. 279-280.

5. Kerr A. K. Organized for Prohibition: A New History of the Anti-Saloon League. N Y.: Yale Univeristy Press, 1985. 293 p.

6. Burke W. The Anti-Saloon League as a political force//The American Academy of Political and Social Science. № 32. Pennsylvania. November 1, 1908. P. 26-37.

7. The American Patriot. Avril, 1912. T.1. № 1 URL: https://www. westervillelibrary.org/antisaloon-american-patriot (Дата обращения: 23.02.2020)

8. The American Patriot. May, 1912. T.1. №2 URL: https://www. westervillelibrary.org/antisaloon-american-patriot (Дата обращения: 23.02.2020)

9. Ellis M. German-Americans in World War I. Enemy Images in American History. L.: Routledge, 1997. 348 p.

10. Westerville public library. URL: https:/cdm15800.contentdm.oclc.org/ digital/collection/p15800coll2/id/2565 (дата обращения: 23.02.2020).

11. Baker P. Statement Refuting Falsehoods and Reciting Facts. Westerville.: A Brown University Library Digital Collection, 1911. 124 p.

12. Okrent D. Last Call: The Rise and Fall of Prohibition. N. Y.: Scribner, 2011. $480 \mathrm{p}$.

13. Hanson D. Wayne Bidwell Wheeler. American National Biography. N. Y.: Praeger, 1999. Vol. 23. 956 p.

14. Okrent D. Wayne B. Wheeler: The Man Who Turned Off the Tap. URL: https://www.smithsonianmag.com/history/wayne-b-wheeler-the-man-whoturned-off-the-taps-14783512/ (Дата обращения: 22.02.2020)

15. Asbury H. The Great Illusion. Garden City, 1950. 279 p.

16. Wheeler W. B. Rum Rebellions: Past and Present. Westerville: The Editors of Encyclopaedia Britannica, 1920. 256 p.

17. Ware H. D. The Anti-Saloon League Wages War in Phoenix, 1910: the Unlikely Case of Frank Shindelbower // Journal of Arizona History. № 39, 1998. P. 141-154.

18. Lerner M.A. Dry Manhattan. Prohibition in New York City, 2008. 360 p.

19. Chalfant H. The Anti-Saloon League - why and what? // The American Academy of Political and Social Science. Pennsylvania. №.109. June 12, 1923. URL: https://www.jstor.org/stable/1015015?seq=1\#metadata_info_tab_contents (Дата обращения: 22.02.2020)

20. Anderson, W.H. Catholics and Prohibition// Lit Digest. 1920. V. 65. P. 44.

21. The New York Time, July 6, 1925. P. 6. 
22. William H. Anderson (William Hamilton Anderson) URL: https://www. alcoholproblemsandsolutions.org/william-h-anderson-biog raphy-williamhamilton-anderson/ (Дата обращения: 18.01.2020)

23. Benavidez L. Prohibition and Religion: William H. Anderson, the Anti-Saloon League, and The Rise and Fall of a Protestant Evangelical Crusade Against Alcohol in New York. URL: https://academicworks.cuny.edu/hc_sas_etds/566/ (Дата обращения: 18.01.2020)

24. William E. Johnson. Westerville Public Library. URL: http://www. westervillelibrary.org/antisaloon-william-johnson (дата обращения: 19.01.2020).

25. McKenzie F. A. "Pussyfoot» Johnson: Crusader, Reformer, a Man among Men. N. Y.: Fleming H. Revell Company, 1920. 273 p.

26. Over 90,000 Bottles Liquor Confiscated // Evening News. 29 April, 1908. 7 p.

27. Downes M. William E. «Pussyfoot» Johnson Scrapbook // Woodson Research Center, Fondren Library, Rice University. Houston, 2003. URL: https://legacy.lib. utexas.edu/taro/browse/rice.html (дата обращения: 19.01.2020).

28. Песни АСЛ. URL: https://www.westervillelibrary.org/File/Get/14771; https://www.westervillelibrary.org/File/Get/14776 (дата обращения: 23.02.2020)

29. Bessie's Mothers // Westerville Ohio Library. URL: https://www. westervillelibrary.org/antisaloon-bessies (дата обращения: 18.01.2020).

30. Charged With Murder // Westerville Ohio Library. URL: https://www. westervillelibrary.org/antisaloon-charged (дата обращения: 18.01.2020).

31. Lou's Cold Bath // Westerville Ohio Library. URL: https://www. westervillelibrary.org/antisaloon-bath (дата обращения: 18.01.2020).

32. Cartoons. Westerville public library. URL: https://cdm15800.contentdm.oclc. org/digital/collection/p15800coll2/ (Дата обращения: 18.01.2020)

33. «Мульторильмы» ACЛ // The Ohio State University. URL: https://cdm15800. contentdm.oclc.org/digital/collection/p15800coll2/id/4299/rec/1 (Дата обращения: 25.02.2020)

34. Cherrington E. Education will keep prohibition in the Constitution // The Anti-Saloon League Museum. Westerville. URL: http://catalog.westervillelibrary. org:81 (Дата обращения: 20.01.2020)

35. Ware, H. D. The Anti-Saloon League Wages War in Phoenix, 1910: the Unlikely Case of Frank Shindelbower // Journal of Arizona History. № 39, 1998. P. 141-154. 